\title{
Health insurance a predominant medium for achieving universal healthcare in India-A farfetched dream?
}

\author{
Rathi A* \\ Dr Baba Saheb Ambedkar Medical College \& Hospital, New Delhi, India
}

\begin{abstract}
In India, there are two kinds of insurances - Social Health Insurance (e.g. Employees State Insurance Scheme) \& Voluntary Health Insurance. Even after years of grappling with health insurances, $71 \%$ of the healthcare costs are borne by the households. CGHS (Central Government Health Scheme), ESI (Employees State Insurance) and private insurance providers are major participants but they often ignore the population that needs the healthcare insurance the most. Self Help Groups and NGOs extend a number of Community based health insurance schemes. However, this covers only less than $1 \%$ of the country's population. ESIS and CGHS taken together constituted $41 \%$ of total spending on insurance. The government has rolled out various schemes like RSBY (Rashtriya Swasthya Bima Yojna) that cover population in informal sector but only the BPL (Below Poverty Line) and marginalized population. Still a large non-formal sector is there that is above the BPL but in dire need of health insurance as they are most susceptible to catastrophic health expenditures and fall below poverty line due to health expenditures. However, achieving universal coverage through compulsory health insurance has several roadblocks like a huge informal sector, uneven income levels, large rural population and variability in government policies. When it comes to healthcare service delivery, private providers account for majority of healthcare expenditure $(\mathbf{7 6 . 7 4 \%})$. While in the public sector, the major providers are public hospitals, outreach centres, medical education, research and training institutes. A comprehensive health insurance scheme is needed instead of fragmented schemes to provide universal health coverage to the whole population.

This short commentary tries to throw light on the inequity of healthcare insurance and service delivery in a complicated healthcare system of urban areas.
\end{abstract}

Keywords: Health Insurance, CGHS, ESI, Catastrophic health expenditure.

Accepted on March 08, 2017

\section{Introduction}

Insurance pays for health care services for those who come under the umbrella of insurance, especially in case of an unforeseen event. Thus it makes healthcare services financially approachable during the event of emergencies and catastrophic contingencies. In India, there are two kinds of insurancesSocial Health Insurance (e.g. Employees State Insurance Scheme) \& Voluntary Health Insurance. The public sector insurance companies and private health insurance companies provide voluntary health insurance schemes.

\section{Ground Reality}

Even after years of grappling with health insurances, $71 \%$ of the healthcare costs are borne by the households (Essential NHA 2004-2005 report) [1]. This covers expenditure on hospital admissions, emergency treatments, outpatient care, family planning services, and childcare services like immunization etc. The recent National Sample Survey (NSS) report reveals that only $12 \%$ of the urban and $13 \%$ of the rural population is under any kind of health protection coverage. In this scenario, it is not a surprise to see that more than onefourth of the total health spending by rural households is sourced from either borrowings or selling of assets [2]. Further,
OOP spending pushes approximately $3.5 \%$ to $6.2 \%$ of the India's population below the poverty line every year [3-5]. State governments source about $12 \%$ of the funding. The central government contributed $6.78 \%$ and firms $5.73 \%$. Amongst financing agents who channelized funds, households channelized $69.4 \%$ of total funds, followed by State Government with $11 \%$ and Central Government at $5.79 \%$. Non-Governmental Organizations (NGOs) and local bodies also contribute an insignificant proportion of total funds.

\section{Providers}

Private providers account for majority of healthcare expenditure (76.74\%). While in the public sector, the major providers are public hospitals, outreach centres, medical education, research and training that accounted for $5.82 \%$, $5.21 \%, 2.50 \%$ and less than $2 \%$ respectively.

The division of healthcare expenditure according to various services, as per the National Health Accounts (NHA 2004-05), has been given in Figure 1 [6]. The central government (Ministry of Health and Family Welfare) spent $26.16 \%$ on curative care while it was $46.92 \%$ for the state governments. As far as the households are concerned, they spent more than $90 \%$ on curative care. 


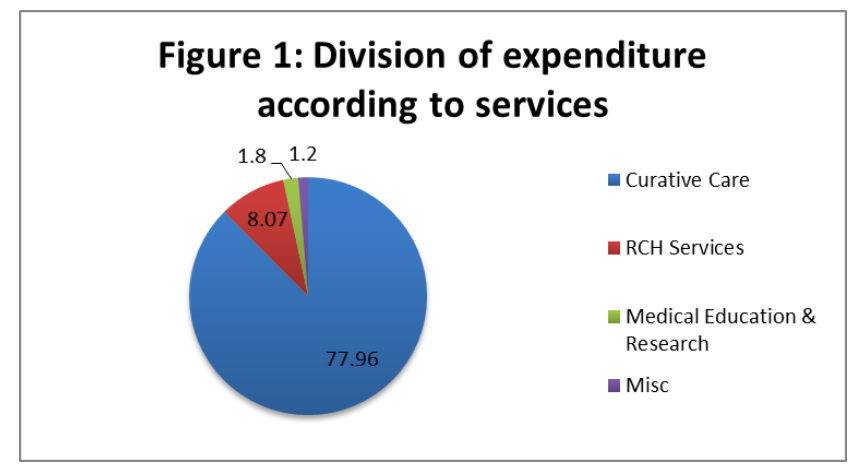

Figure 1. Division of expenditure according to services.

In India, General Insurance Companies also called as Non-Life Insurance Companies provide health insurance schemes to the public in the form of individual or group policies against the payment of a premium. Self Help Groups and NGOs extend a number of Community based health insurance schemes. However, this covers only less than $1 \%$ of the country's population. Total expenditure on insurance was INR 36,609 million, of which INR 19,306 million (52.7\%) was incurred by public insurance companies. ESIS (Employees' State Insurance Scheme) and CGHS (Central Government Health Scheme) taken together constituted $41 \%$ of total spending on insurance.

\section{History of Health Insurance}

The history of health insurance in India dates back to 1940s-1950s when the civil servants (CGHS) and formal sector workers (ESIS) were enrolled into a contributory but heavily subsidized health insurance programs [7]. After more than 50 years of experience, CGHS \& ESI currently covers $5 \%$ of the population, covering 3 million and 55.5 million beneficiaries respectively [8]. Since 2007, Owing to the commitment by the government to increase public spending in healthcare from $1 \%$ to $2-3 \%$, India has witnessed a host of new initiatives by the central and state governments who have devised ways to increase spending through innovative schemes. The most important task these schemes are meant to do is to enhance access and availability of essential healthcare services. They also intend to protect households from financial catastrophes. The major central government schemes are National Rural Health Mission (NRHM), and Rashtriya Swasthya Bima Yojana (RSBY). The State specific initiatives include Rajiv Aarogyasri (Andhra Pradesh), Kalaignar's Insurance Scheme for Life Saving Treatment (Tamil Nadu), Vajapayee Arogyasri \& Yeshasvini programs in Karnataka, etc. These demand-side financing mechanisms entitle poor and other vulnerable households to choose cashless healthcare from a pool of empanelled private or public providers [9].

\section{Critical analysis of health insurance}

However the health insurance scheme has its own loopholes and is susceptible to various threats like over utilization through over prescription. There are various institutional challenges that need to be overcome before implementing these schemes at a wide level. Schemes like ESI \& CGHS cover the population in formal sector and schemes like RSBY cover population in informal sector but only the BPL (Below Poverty Line) and marginalized population. Still a large non-formal sector is there that is above the BPL but in dire need of health insurance as they are most susceptible to catastrophic health expenditures and fall below poverty line due to health expenditures. Thus schemes like Arogyashri \& Kalainger should be followed so that maximum population can avail health insurance benefits and universal health coverage can be achieved.

However, achieving universal coverage through compulsory health insurance has several roadblocks like:

1. A huge informal sector-that is not covered by any scheme.

2. Uneven income levels-it is difficult to categorize and charge different premiums.

3. Large rural population-that is both poor and inaccessible, moreover they are not informed and are most likely to fall prey to catastrophic health expenditures.

4. Variability in government policies-India being a democracy, government changes often and policy of one is often incongruent with that of the previous one and ultimately, the various schemes bear the brunt.

The private health insurances are basically for people who can afford. They charge hefty premiums and give limited coverage primarily just to in-patients. The biggest disadvantage is that they do not cover outpatient charges and fees though the majority of health expense is on OPD only $(60 \%$ of the total expenditure). Thus instead of giving comprehensive health coverage they provide mainly for accidents and sudden hospitalizations

ESIS contributions are progressive in nature as they are calculated as a percentage of income and no fixed sum is charged. The major disadvantage of this scheme is that only the poorest are subsidized (employees earning 15,000 per month or less). Employees who earn more are left out hence it is not a very equitable scheme. It would have been better situation if the high wage earners were also included (by paying a higher premium) and thus a larger population would have been effectively covered. Though the horizontal expansion of this scheme is limited but the advantage that it offers over many other health insurance schemes is the vertical expansion of the services it covers. The depth of services provided by ESI \& CGHS is incomparable as they provide for not just in-patient \& chronic diseases but also maternity benefits, prevention, wellness, AYUSH \& OPD services. The remarkability of ESIS, apart from providing a plethora of services like preventive, outpatient and inpatient medical care, is that it also provides compensatory cash benefits for loss of wages, disability benefits distinguished by permanent and temporary disability, and a maternity cash program among other benefits. It also provides preventive care especially in the case of HIV and screening of other occupational hazard related diseases, though the outreach of these services are rather poor.

More recently schemes like Yeshasvini that cover both APL (above poverty line) and BPL populations across the rural Cooperatives in Karnataka perform better in terms of pooling financial risks. However schemes like Yeshasvini, Rajiv 
Arogyashri, RSBY, Kalinger, Vajpayee Arogya Scheme lack in providing the depth of services. Mostly cover just the inpatient \& chronic diseases except for RSB which also gives the maternity benefits. However, the exceptions include the benefit package for Yeshasvini Health Insurance Scheme in Karnataka, which covers both secondary and tertiary care. The benefit package under RSBY is mainly focused on the provision of secondary care. Primary care, which includes preventive services, is not included in any of the schemes for various reasons.

Hence a comprehensive health insurance scheme is needed instead of fragmented schemes to provide universal health coverage to the whole population. All these schemes can be merged so that one can complement the other and majority of the population gets covered.

A high level expert-group of the Planning Commission gave some important recommendations for achieving Universal Health Coverage (UHC) for India [10,11]. Some salient points that can be acted upon to solve the current situation are:

- Health care services will be made available through the public sector and contracted-in private facilities (including NGOs and non-profits).

- Private providers will have to make sure that at least $75 \%$ of outpatient care and $50 \%$ of in-patient services are offered to citizens under the national health package (NHP).

- The private providers will be given reimbursement at fixed rates and their activities will be regulated to ensure equity and quality.

- Key recommendations on health financing and financial protection are that government (Central government and states combined) should increase public expenditures on health to at least 3\% of GDP by 2022 .

- The principal source of health care financing should be general taxation - complemented by additional mandatory deductions for health care from salaried individuals and taxpayers, either as a proportion of taxable income or as a proportion of salary.

- Ensuring availability of free essential medicines by increasing public spending on drug procurement.

- It recommended that user fees of all forms be dropped as a source of government revenue for health.

- Currently, majority of funds are devoted to tertiary level care. However, it is recommended that a lot of emphasis should be put on primary health care and at least $70 \%$ health expenditure should be spent on it, including general health information and promotion, curative services at the primary level, screening for risk factors at the population level, and cost-effective treatment.

- It is recommended that every citizen should be issued an IT-enabled National Health Entitlement Card (NHET) that will ensure cashless transactions, allow for the mobility in the country, and contain personal health information.

- Training and capacity building of healthcare providers at all levels will provide quality care.
- A redressal mechanism should be strengthened and a fully functional monitoring mechanism should be in place for quick feedback and improvement in the system.

Hence, the path to UHC is long and hard but strong strides need to be taken in the direction to improve the existing healthcare delivery system.

\section{References}

1. Report of the National Commission on Macroeconomics and Health: Ministry of Health and Family Welfare Government of India (2005), New Delhi India.

2. Berman P, Ahuja R, Bhandari L. The impoverishing effect of healthcare payments in India: New methodology and findings. Economic \& Political Weekly. 2010; 45: 65-71.

3. National Health Accounts India (2009). New Delhi: Ministry of Health and Family Welfare Government of India.

4. Shahi AK, Gill HS. Origin, Growth pattern and trends: A study of Indian health insurance sector. IOSR Journal of Humanities and Social Science. 2013; 12: 1-9.

5. A Critical Assessment of the Existing Health Insurance Models in India: A Research Study Submitted By Public Health Foundation of India (2011). New Delhi: Planning Commission of India.

6. Government of India, Ministry of Statistics and Programme Implementation (2015). NSSO 71st Round (January-June 2014): Key indicators of social consumption in India health.

7. Garg CC, Karan AK. Reducing out-of-pocket expenditures to reduce poverty: A disaggregated analysis at rural-urban and state level in India. Health Policy and planning. 2009; 24: 116-128.

8. Van Doorslaer E, O’Donnell O, Rannan-Eliya RP, et al. Effect of payments for health care on poverty estimates in 11 countries in Asia: An analysis of household survey data. The Lancet. 2006; 368: 1357-1364.

9. Prinja S, Chauhan AS, Karan A, et al. Impact of publicly financed health insurance schemes on healthcare utilization and financial risk protection in India: A Systematic Review. PLoS One. 2017; 12: e0170996.

10. Bang A, Chatterjee M, Dasgupta J, et al. High level expert group report on universal health coverage for India. New Delhi, Planning Commission of India; 2011.

11. Thakur J. Key recommendations of high-level expert group report on universal health coverage for India. Indian J Community Med. 2011; 36: 84-85.

\section{*Correspondence to}

Akanksha Rathi,

Dr Baba Saheb Ambedkar Medical College \& Hospital

New Delhi, India 